\title{
㐘 \\ O TRABALHO DE CAMPO NA \\ GEOGRAFIA: CARACTERÍSTICAS \\ FUNDAMENTAIS E UM CONVITE À
}

ESCUTA

- RENATO COIMBRA FRIAS*

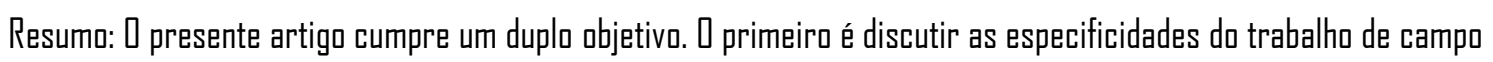
na Geografia. Para tal fim, apresenta-se um panorama histórico e uma revisão bibliográfica sobre o papel da trabalho de campo na disciplina, buscanda definir quais sãa as suas características fundamentais. 7 segunda objetivo é apresentar ferramentas de análise, noções e práticas de pesquisa que permitam aos gé́grafos realizar trabalhos de campa facados no estudo dos sons do munda. Para issa, discute-se o papel central que a visãa passui na produçãa e na comunicação do conhecimento geográfico, de modo a demonstrar, em seguida, as possibilidades que se abrem quando consideramos também a nossa escuta. Por último, é apresentado um conjunto selecionado de noções, conceitos e práticas de campo que podem auxiliar no planejamento de uma investigação empírica dedicada ao som e à espacialidade.

Palavras-Chave: Trabalho de campo; paisagem sonora; métodos fonográficas; caminhadas sonoras.

Nota inicial sobre a área de estudos da Geografia

O trabalho de campo não é um procedimento metodológico exclusivo da
Geografia. Dessa forma, afirmamos juntos com Serpa (2006:9), que "uma reflexão sobre a importância do trabalho de campo nesta disciplina requer a compreensão de sua especificidade frente às outras 
disciplinas". Nesse sentido, para que possamos discutir o trabalho de campo na Geografia, cabe aqui apontar o que há de especifico no conhecimento geográfico frente às outras formas de conhecimento. Para o mesmo autor,

Poucos estariam dispostos a contestar o papel central do 'espaço' enquanto conceito na produção do conhecimento geográfico. Isso é, com certeza, a especificidade maior da Geografia, sua razão de ser perante as outras ciências. Os estudos da dimensão espacial da sociedade e da dimensão social do espaço colocam a Geografia diante da árdua tarefa de operacionalização do conceito de "espaço" em sua dimensão empírica (Serpa, 2006:10).

Gomes (2009:26-27), em complemento, afirma que o terreno da ciência geográfica não se define pela posse de um objeto específico, nesse caso, "o espaço”. O que delimita a área de interesses da Geografia, para o autor, é muito mais um modo de pensar e indagar o mundo do que a tomada de uma parcela específica desse mundo como objeto de estudo. É, nas suas palavras, muito mais o tipo de questão que é dirigida a um fenômeno do que o fenômeno em si que vai definir o teor geográfico ou não de uma pesquisa. E o tipo de questão construído pela ciência geográfica é aquele que se interroga sobre a ordem espacial dos fenômenos estudados.

Basta lembrar que a arquitetura, a história e a economia também podem tomar o espaço como objeto de estudo e o que determina a especificidade de cada uma dessas áreas do pensamento são as questões por elas levantadas. Todas elas, juntas com a Geografia, podem dividir o mesmo objeto de pesquisa. No entanto, como afirma Gomes (2009:27), uma análise geográfica se delineia quando a nossa questão central está preocupada a ordem espacial dos fenômenos estudados. Ou seja, haverá sempre uma geografia quando a dispersão espacial construir a questão central do nosso problema. Ou ainda, a Geografia existe em qualquer fenômeno em que haja uma ordem de dispersão espacial.

Essa perspectiva sobre a área de estudos da Geografia nos interessa aqui pois permite que discutamos a importância do trabalho de campo na disciplina sem que precisemos nos ater às especificidades epistemológicas e metodológicas dos subcampos da Geografia Física e da Geografia Humana. O que nos interessa é o que elas possuem em comum: o interesse pela dimensão espacial dos fenômenos que estudam. Estejam os geógrafos dedicados ao estudo dos processos erosivos em uma bacia hidrográfica ou à difusão de um tipo de comércio em uma cidade média, as duas 
perguntas fundamentais para esses pesquisadores vão ser sempre duas: “onde?” e "por que aqui?".

Feito esse esclarecimento, podemos, agora, passar à discussão sobre o papel do trabalho de campo na Geografia. Comecemos, portanto, revisando as diferentes formas como esse procedimento metodológico foi encarado ao longo da história do pensamento geográfico.

\section{O trabalho de campo na Geografia: breve panorama histórico}

Zusman (2011) nos oferece um interessante panorama sobre como a Geografia encarou o trabalho de campo ao longo das transformações teóricas pelas quais passou a ciência nos últimos séculos. A autora apresenta quatro maneiras de conceber o trabalho de campo, cada uma delas atrelada um momento histórico e a uma forma especifica de concepção teórica sobre a Geografia.

A primeira forma de conceber o trabalho de campo estaria associada às atividades de exploração territorial realizadas na virada do século XIX para o $\mathrm{XX}$, quando a Geografia se consolidava como um conjunto de conhecimentos úteis aos objetivos dos Estados nacionais e dos Impérios europeus (Zusman, 2011:18).
Nesse contexto, os trabalhos de campo possuíam forte caráter exploratório, com o objetivo de levantar as características geológicas, climáticas e hidrológicas, realizar levantamentos cartográficos e a coleta de amostrar da fauna e da flora.

Em um segundo momento, já na primeira metade do século XX, o contex to é de consolidação da Geografia enquanto disciplina universitária. Zusman explica que os pesquisadores da área buscavam desenvolver suas investigações e construir as suas representações do mundo a partir de conceitos tomados como centrais na Geografia: paisagem e região. O empirismo ganha força na disciplina e, assim sendo, o trabalho de campo aparece como estratégia metodológica importante na Geografia, diferenciando-a das outras áreas do saber e legitimando-a cientificamente. O campo, nesse contexto, passa a ser entendido como um equivalente do laboratório das ciências exatas, na medida que permitia o estudo dos processos que interessavam à disciplina e a avaliação de hipóteses pelos geógrafos (Zusman, 2011:20).

No entanto, como já dissemos, o trabalho de campo nunca foi um procedimento metodológico exclusivo da Geografia. Então, neste momento, o que diferenciava o trabalho de campo geográfico dos trabalhos de campo realizados pelos etnógrafos, por exemplo? 
Zusman (apoiada em Price, 2001) argumenta que estes últimos se dedicavam à coleta de relatos dos indivíduos pertencentes aos grupos estudados, enquanto os geógrafos continuavam reticentes em considerar relevante a interação com as populações locais e a valorizar a contribuição dos seus saberes no processo de produção do conhecimento (Zusman, 2011:20). Para aqueles que entendiam a Geografia como a ciência da paisagem, o trabalho de campo consistia em uma atividade, primeiramente, visual: ler as formas visíveis, fotografá-las e classificálas, a partir da sua comparação com as formas que constituíam outras paisagens. Ainda que em alguns casos o interesse estivesse voltado para formas passadas, o campo permitiria "obter gradualmente uma imagem da paisagem cultural do passado oculto por trás da paisagem do presente" (Sauer, 1940 apud Zusman, $2011: 20$ ).

Zusman (2011:21) argumenta que essa concepção começa a se modificar a partir da década de 1970, com a ascensão da Geografia crítica, dando origem a uma nova perspectiva sobre o estatuto do trabalho de campo na disciplina. Nesse novo momento, a Geografia passa a ser entendida como uma ciência social comprometida com a transformação da sociedade. Nesse sentido, o trabalho de campo pressupõe a necessidade do pesquisador envolver-se com as problemáticas sociais das comunidades por ele estudadas.

$$
\begin{aligned}
& \text { No marco dessas posturas } \\
& \text { interpretativas, a Geografia era } \\
& \text { entendida como uma ciência social } \\
& \text { que buscava, entre outros objetivos, } \\
& \text { analisar as causas estruturais da } \\
& \text { pobreza e das desigualdades sociais. } \\
& \text { Essa concepção da geografia levou a } \\
& \text { outorgar um protagonismo às } \\
& \text { sociedades locais do trabalho de } \\
& \text { campo, até então raramente levadas } \\
& \text { em consideração como vozes } \\
& \text { relevantes na investigação. A } \\
& \text { interação do especialista com os } \\
& \text { setores populares nos seus locais de } \\
& \text { trabalho ou residência se apresentava } \\
& \text { como a forma mais adequada para a } \\
& \text { abordagem daquelas temáticas, na } \\
& \text { medida que outorgava à disciplina } \\
& \text { uma relevância social e } \\
& \text { potencializava a sua capacidade } \\
& \text { transformadora (Zusman, 2011:21). }
\end{aligned}
$$

Essa nova concepção vai levar autores como Yves Lacoste (2006 [1977]) a levantar questionamentos a respeito da responsabilidade do pesquisador $\mathrm{e}$ às relações que deveriam estabelecer-se entre o intelectual e a população que é seu centro de interesse científico. É normal que o pesquisador se desinteresse da sorte da população que ele estudou? É normal que 
esta permaneça na ignorância das pesquisas das quais foi objeto? Essas são algumas das questões que ilustram quais passam a ser as preocupações dos geógrafos ao pensarem os seus trabalhos de campo no contex to da Geografia crítica.

Para Zusman, a quarta maneira de conceber o trabalho de campo na Geografia se consolida a partir da década de 1990, com a aproximação dos geógrafos dos estudos etnográficos e a consequente redefinição das relações entre a academia e o campo. Segundo a autora, é a partir desse marco que começa a se compreender que o trabalho de campo não pode ser reduzido ao momento em que o investigador entra em contato com os lugares $\mathrm{e}$ as comunidades que compõem o corpo empírico da investigação. Ou seja, sob este ponto de vista, o trabalho de campo se faz presente desde o inicio da formulação da investigação. A interpretação teórica define o tipo de atividades e perguntas que serão realizados no trabalho de campo, ainda que estas possam acabar entrando em tensão, ser desafiadas ou enriquecidas pelas informações obtidas no próprio campo e delas derivem uma nova perspectiva teórica (Escolar, 1998 apud Zusman, 2011:21).

Ainda segundo Zusman, outras duas mudanças ocorreram nos trabalhos de campo em Geografia a partir da aproximação com o método etnográfico. A primeira foi o maior peso dado à perspectiva dos informantes frente a dos estudiosos, o que poderia permitir que as pesquisas em campo oferecessem uma perspectiva mais heterogênea dos processos espaciais analisados. A outra mudança, seria um interesse maior dos geógrafos em refletir sobre a posição do investigador em campo, seus condicionantes sociais e políticos, e as relações de poder que se estabelecem entre o investigador e seus informantes (Zusman, 2011:23).

\section{O trabalho de campo na Geografia: características fundamentais}

Após esse breve e esclarecedor panorama apresentado por Zusman, podemos discutir as características fundamentais do trabalho de campo na Geografia. Nas palavras da própria autora,

As investigações atuais na Geografia geralmente combinam a observação (visual) do campo com a observação participante, o mapeamento participativo, a realização de entrevistas semiestruturadas ou de histórias de vida. A observação pura é considerada, geralmente, uma etapa exploratória do reconhecimento do terreno. Esse momento costuma ser 
útil para avaliar a validez da investigação que deseja se realizar e das perguntas que a orientam, ou para reformulá-las. Porém, a interações com os informantes é o que abre a possibilidade de descrever a vida social e espacial e é o que permite incorporar a perspectiva de membros da comunidade (Zusman, 2011:25).

Zusman defende, portanto, que as diferentes formas de se conceber o trabalho de campo não só coexistem hoje como muitas vezes apresentam-se de forma amalgamada. No entanto, o que há de comum nessas diferentes formas, o que nos permite dizer que, nos exemplos citados pela autora, temos trabalhos de campo geográfico?

Tanto Alentejano e Rocha Leão (2006) quanto Serpa (2006) enxergam o trabalho de campo na Geografia como uma ferramenta importante na superação da "dicotomia sociedade-natureza" e das "dicotomias e ambiguidades características da geografia”, respectivamente.

No entanto, nos primeiros parágrafos deste texto expusemos como tais dicotomias, especialmente aquela ligada à divisão entre Geografia Física e Geografia Humana, é decorrente da concepção teórica que se tem da disciplina e não seria um procedimento metodológico como o trabalho de campo que nos permitiria superar essa divisão. Por outro lado, a indicação que o trabalho de campo permitira a superação dessa dicotomia, denota que há, nesta prática, algo que é comum aos dois subcampos e, portanto, fundamental ao pensamento geográfico.

Driver (2000) reconhece que em meio à heterogeneidade de significados ligados à ideia de "campo" na Geografia, é possível identificar sempre a referência a três elementos que costumam aparecer intimamente entrelaçados: a prática, a representação e a espacialidade. Apesar de tal constatação não ser longamente desenvolvida pelo autor, acreditamos que ela aponte um caminho interessante para identificarmos o lugar do trabalho de campo na Geografia hoje.

Primeiramente, quando pensamos em trabalho de campo em Geografia, pensamos, usualmente, em "atividades práticas”. Isso não significa um empirismo puro, já que a concepção e a escolha das atividades a serem realizadas em campo pressupõem uma reflexão teóricametodológica por parte do pesquisador. Também não significa dizer que é possível separar completamente, no curso da pesquisa, teoria e prática. No entanto, seja com o objetivo de realizar uma exploração inicial, coletar dados primários ou para a realização de experimentos, a ida a campo é tomada por todos nós como uma etapa da 
pesquisa que extrapola a simples construção teórica do objeto de pesquisa. $\mathrm{O}$ trabalho de campo é o momento onde vamos realizar as atividades prática, empíricas, necessárias para testarmos nossas hipóteses iniciais a partir da coleta de dados e da observação com as realidades geográficas que nos interessam.

Segundamente, a ida a campo sempre envolve a construção de representações. Latour demonstrou isso de maneira brilhante, expondo todas as mediações necessárias para que a coleta de dados empíricos em campo se transformasse em gráficos, textos, diagramas, mapas e outras formas de se representar a realidade em estudo. Destacamos aqui um trecho onde ele descreve a coleta de amostras vegetais por uma botânica em um campo na Amazônia, ilustrando a relação entre a atividade prática e a construção de representações:

Cada planta que ela remove representa milhares da mesma espécie, presentes na floresta, na savana e na zona limítrofe entre ambas. Edileusa [a botânica] não está colhendo um ramalhete, está reunindo as provas que quer preservar como referência (aqui, em outra acepção da palavra). Deve ser capaz de encontrar o que escreve em seus cadernos e recorrer a eles no futuro. A fim de poder dizer que a
Afulamata Diasporis, uma planta comum da floresta, é encontrada na savana, mas apenas à sombra de outras que conseguem sobreviver ali, ela tem de preservar, não a população inteira, mas uma amostra que se comportará como uma testemunha silenciosa de sua assertiva. Na braçada que ela acaba de colher, podemos identificar dais traços de referência: de um lado, uma economia, urna indução, um atalho, um funil onde Edileusa toma uma única folha de grama como representante de milhares de folhas de grama; de outro, a preservação de um espécime que mais tarde atuará como fiador quando ela própria ficar em dúvida ou, por diversos motivos, seus colegas duvidarem de suas afirmações (Latour, 1999 [2001]:48).

Por último, retomemos a questão da espacialidade, destacada nos nossos parágrafos iniciais. Como dissemos, o trabalho de campo não é um procedimento metodológico exclusivo dos geógrafos. Etnógrafos, ecólogos, pedólogos, geólogos e tantos outros pesquisadores realizam essa atividade como etapa importante do desenvolvimento dos seus estudos. A espacialidade é, no entanto, o elemento fundamental que vai diferenciar o trabalho de campo do geógrafo frente aos outros. Isso não significa que o mapeamento $\mathrm{e}$ outras formas de organizar o mundo 
espacialmente não sejam importantes para as outras áreas do pensamento. Obviamente são. Mas é a espacialidade dos fenômenos e a pressuposição que a análise dessa espacialidade pode revelar aspectos importantes sobre eles que motiva o geógrafo a ir a campo. A coleta de dados na geografia é orientada pela busca por uma compreensão da organização espacial dos seus objetos de estudos.

Nesse sentido, podemos afirmar que, independente do tipo de pesquisa que se realiza na geografia, seja ela de caráter natural ou social, o trabalho de campo assume a função de etapa metodológica onde um conjunto de atividades práticas vai permitir a construção de uma representação do fenômeno estudado no qual esteja destacada a sua dimensão espacial. De forma simples e direta, este nos parece ser o aspecto fundamental que diferencia o trabalho de campo na Geografia frente aos outros.

Há, ainda, um quarto aspecto, ignorado por Driver (2000), que gostaríamos de tratar aqui: o peso dado pelos geógrafos nas suas abordagens e, consequentemente, nos trabalhos de campo, aos aspectos visuais do mundo.

\section{A Geografia e os aspectos visuais do mundo}

Junto com Gomes e Ribeiro (2013), gostaríamos de apontar que o raciocínio geográfico sempre esteve associado a um imprescindível aparelhamento visual, atendendo, desde seus primórdios, a um verdadeiro imperativo gráfico. Essa necessária associação surge mesmo na denominação da disciplina: Geo + grafia, contendo, assim, em seu próprio corpo, a concepção de informações que estão gravadas, inscritas.

Para ilustrar essa afirmação, podemos lembrar que a descrição, classificação e interpretação da paisagem configura um dos campos de estudo mais tradicionais na Geografia que, desde os seus primórdios, está ancorado nos aspectos visíveis do mundo. De Sauer (1998 [1925]) a Cosgrove (1985), pouca atenção foi dada aos aspectos não-visuais da paisagem e dos lugares. O que é descrito e compreendido nessas pesquisas é, em grande parte, aquilo que é visto.

Esse imperativo visual da Geografia é revelado também na forma como comunicamos o conteúdo produzido pela disciplina: mapas, desenhos, gravuras, pinturas, fotografias, diagramas, fluxogramas e esquemas corroboram a ideia de que a informação geográfica foi, desde os seus primórdios, informação gráfica. 
Não por acaso, autores de linhas de pensamento distintas, como Gregory (1994), Smith (2000), Rose (2003) e Cosgrove (1985) reconheceram o conhecimento geográfico como sendo "uma forma especial de visualização”, como afirmou o geógrafo britânico Halford Mackinder muitos anos antes, em 1904 (apud RYAN, 1994). No Brasil, autores como Gomes (2013) e Novaes (2011), produziram relevantes trabalhos sobre o tema.

Esse "ocularcentrismo", ou seja, esse enfoque centrado unicamente no que é visível, reflete-se também na forma como conduzimos os nossos trabalhos de campo.

Como nos relata Schwartz (1996), Humboldt levava sempre um "time de ilustradores" (p.19) para seus trabalhos de campo e fazia uso frequente das imagens em seus relatos. Como membro da Academia de Ciências, Humboldt inclusive visitou, em 1838, o estúdio de um dos grandes inventores da fotografia, Louis Jacques Mandé Daguerre, pois estava intensamente interessado no processo de fixação de imagens através da "câmara obscura". Alguns anos mais tarde, a câmera fotográfica se tornaria uma ferramenta “indispensável” para a realização de trabalhos de campo pelo geógrafo (SCHWARTZ, 1996 apud NOVAES, 2011).

Ou seja, na Geografia, tradicionalmente, métodos e instrumentos de trabalho são escolhidos com o propósito de potencializar a nossa capacidade de "ver o mundo", de observá-lo e descrevê-lo a partir dos seus atributos visuais, sejam eles as feições de um relevo ou a morfologia de uma cidade.

Neste contexto, gostaríamos de argumentar a favor de uma Geografia interessada nos aspectos não-visuais dos espaços estudados, mais especificamente, atenta às possibilidades que se abrem ao adotarmos um referencial teórico, uma abordagem e um conjunto de métodos voltados para o que se ouve e não apenas para o que se vê. Cabe, então, explicar quais são os fatores que justificariam o interesse dos geógrafos pelos sons do mundo.

\section{Um convite à escuta}

Boa parte dos sons que ouvimos no nosso dia-a-dia, como os roncos de motores, o estalo de um galho ou os ruídos ferroviários, são apenas resíduos de determinadas atividades mecânicas. A outra parte é composta por emissões sonoras destinadas à comunicação, como as buzinas dos carros e anúncios de ambulantes. Juntas, formam uma composição sonora, cacofônica e 
involuntária, presente na maioria das grandes cidades, que é percebida, em maior ou menor grau, por qualquer um dos seus citadinos.

Na perspectiva de Thibaud (2011), a composição formada pelos sons de um ambiente são a expressão pública de uma forma específica de vida, de uma maneira particular de convivência. Pessoas caminhando pelas ruas e conversando umas com as outras, carros circulando, a construção de um novo edifício, enfim, há uma série de atividades e práticas sociais que são audíveis e nos dão acesso ao que acontece em um determinado lugar. Além disso, a largura das ruas, a altura dos prédios, o tipo de revestimento das construções, a presença ou ausência de arborização e outros aspectos ligados à morfologia local também afetam a sonoridade resultante das ações típicas de um espaço urbano, gerando reverberações e influindo sobre o alcance espacial de um determinado som, por exemplo. Dessa forma, também podem ser analisados por uma metodologia que privilegie o som no estudo desses lugares.

Enquanto a visão tende a implementar uma distância entre quem percebe e o que é percebido, e enquanto o olfato tende a produzir fenômenos excessivamente difusos e voláteis, a audição pode agregar o afetivo com o cognitivo, o universal com o singular de uma maneira muito equilibrada. Através da visão nós observamos um mundo diante de nós, presumimos um distanciamento entre quem vê e o que é visto (WYLIE, 2007). Já o som não está “aqui” ou “ali”, ele é omnidirecional. Diferentemente da cor, que permanece "colada” ao objeto, o som tem a capacidade de se separar de sua fonte e difunde-se em muitas direções. Estamos rodeados de sons que se propagam ao redor e vêm de todos os lugares ao mesmo tempo. Através da audição, o mundo não se apresenta à nossa frente, mas ao nosso redor.

Alguém poderia argumentar que cheiros e aromas também permitem essa experiência imersiva que o som nos fornece. No entanto, a nossa audição, diferentemente do que acontece com o nosso olfato, é suficientemente acurada para qualificar propriamente e distinguir precisamente um ambiente de outro. Comparando-se a gravação realizada em uma área de comércio popular do Rio de Janeiro/Brasil (https://bit.ly/368e54p) e outra em uma estação de metrô em Santiago/Chile (https://bit.ly/2NISoDp), podemos notar como as ações e a morfologia local afetam o que se ouve e distinguem bem esses dois lugares. O mesmo não seria possível caso privilegiássemos cheiros e aromas. 
Soma-se a esses argumentos o fato de possuirmos, hoje, técnicas disponíveis e acessíveis para o registro e posterior análise do som. Podemos gravar, documentar e descrever a dinâmica de um determinado ambiente através de registros sonoros, que podem ser utilizados para projetar e desenvolver uma etnografia sensorial do mundo urbano. $\mathrm{O}$ mesmo não acontece com os estímulos olfativos, o que impõe uma série de impedimentos metodológicos à pesquisa.

Em suma, quando "ouvimos um lugar", ouvimos uma organização social específica do som e também a forma como as pessoas interagem e se relacionam umas com as outras. O som é tanto a expressão quanto o meio de diferentes modos de interação e organização da vida social (THIBAUD, 2011). Em termos sonoros, faz diferença perceber com que frequência os motoristas acionam as suas buzinas, qual marca e tipo de carros eles dirigem, qual estação de rádio podem ser ouvidas pelas suas janelas abertas e quais mercadorias são anunciadas pelos comerciantes. Através dos seus estilos-de-vida, os moradores de uma cidade também produzem uma espécie de atmosfera (BOHME apud THIBAUD, 2011) ou, como colocou Schafer (2011), uma paisagem sonora.

\section{Paisagem sonora e métodos fonográficos}

Além de alguns trabalhos isolados, como o artigo sobre as "paisagens olfativas" de Porteous (1990), na Geografia, os autores que buscaram romper com esse "ocularcentrismo", dedicaram-se às relações entre som e espacialidade (TORRES, 2010; WISSMANN, 2014; MALANSKI 2017, FRIAS 2018; entre outros). Estes são, em sua maioria, tributários das reflexões apresentadas pelo compositor, escritor e educador canadense Raymond Murray Schafer. Em seu livro "A afinação do mundo" (SCHAFER, 2011), o autor nos apresentou o conceito de paisagem sonora (soundscape) e uma série de outras noções (como objeto sonoro, evento sonoro, sons fundamentais, marcos sonoros e sinais sonoros) que compunham o instrumental teóricometodológico do seu projeto acústico ${ }^{1}$. Podendo ser entendida também como um ambiente sonoro, a paisagem sonora corresponde a

\footnotetext{
“(...) qualquer porção do ambiente sonoro vista como um campo de estudos. O termo pode referir-se a ambientes reais ou a construções abstratas, como composições musicais e montagens de fitas, em particular
} 
quando consideradas como um ambiente" (SCHAFER, 2011, p. 366).

Em um trabalho de campo dedicado às relações entre sons e espacialidade, nos deparamos com o desafio de levantar dados que permitam uma análise geográfica a partir da dimensão sonora do espaço. Para tal feito, muitos autores vêm utilizando os chamados métodos fonográficos de pesquisa, ou seja, instrumentos de pesquisa eu permitam a escuta in loco, gravação de áudio e sua posterior edição, reprodução e audição (GALLAGHER e PRIOR, 2014).

Como aponta Lorimer (2007), gravações de áudio em trabalhos de campo têm sido utilizadas para registrar os sons de animais selvagens, como o canto dos pássaros e determinadas dinâmicas de caça, migração e reprodução que não poderiam ser registradas com a presença humana (KRAUSE, 2013).

Métodos fonográficos também já foram utilizados em trabalhos de antropologia e etnomusicologia: no registro práticas e performances musicais e sonoras (ANDERSON et al, 2005); análise da relação entre letras de música e construção de identidade em diferentes escalas geográficas (LEHR, 1983); coleta de depoimentos sobre o papel do som e da música na formação de identidades locais (BOLAND, 2010); em pesquisas sobre como música e som se relacionam com poder e política (Gallagher, 2011); em pesquisas documentais e entrevistas sobre o papel do som e da música no espaço de trabalho, na cidade, no campo e na vida cotidiana (Bull, 2000; Corbin, 1998; DeNora, 2000; Garrioch, 2003; Jones, 2005; Matless, 2005); na arqueologia acústica (Smith, 2004); e, por fim, em etnografias focadas no papel da música como mediadora da memória (Anderson, 2004).

Uma característica comum a todos esses trabalhos citados é o grande peso dado à voz humana frente aos outros elementos sonoros que, caso fossem considerados, possibilitariam outras abordagens do material coletado.

Como explicam Gallagher e Prior (2014), tradicionalmente, métodos fonográficos têm exercido um papel importante na coleta de dados qualitativos na Geografia, através da gravação de relatos orais para subsequente transcrição em texto. Tais método são, geralmente, tomados como formas de "escutar", permitindo que a "voz" dos respondentes seja "ouvida". No entanto, esse processo de transcrever em texto dados fonográficos é geralmente vista de forma naturalizada, pouco problematizada, e tem sido assunto de pouca reflexão.

O pressuposto de que se deve privilegiar o conteúdo verbalizado em 
relação aos demais aspectos sonoros contidos na gravação de uma entrevista é particularmente problemático para geógrafos, uma vez que isso tende a silenciar algumas especificidades geográficas contidas no som: sotaques regionais, a acústica, ambiência e ressonâncias dos espaços em que as entrevistas são realizadas, entre outros (GALLAGHER e PRIOR, 2014:04).

Buscando ampliar as possibilidades de investigação das relações entre sons e espacialidade na Geografia, gostaríamos de apresentar, aqui, um conjunto de noções e práticas de campo que, apesar de estarem longe de esgotar o referencial e as possibilidades existentes, podem servir como um ponto de partida para aqueles interessados neste campo de estudos.

Inicialmente, debateremos como as noções de sinal sonoro, som fundamental e marca sonora, cunhadas por Schafer (2011), podem nos orientar na análise dos sons encontrados em um trabalho de campo. Em seguida, discutiremos como as noções de ponto de vista, composição e exposição, advindas das artes visuais, oferecem inspiração também para pensarmos a dimensão sonora dos espaços que visitamos. Por último, debateremos a utilização das caminhadas de escuta e observação no trabalho de campo de
Geografia, apresentando algumas orientações básicas a respeito do planejamento e condução do campo.

\section{Sinais sonoros, sons fundamentais e marcas sonoras}

Para Schafer (2011, p.25-26), “o analista da paisagem sonora precisa fazer, em primeiro lugar, é descobrir os seus aspectos significativos, aqueles sons que são importantes por causa da sua individualidade, quantidade ou preponderância”. Ou seja, nossos trabalhos de campo, quando voltados para questões ligadas ao som, devem considerar duas questões iniciais: o que queremos ouvir em campo e como descrever e classificar aquilo que é ouvido?

O mesmo Murray Schafer propõe três noções para a análise da paisagem sonora que nos serão úteis neste estudo: sinais sonoros, sons fundamentais e marcas sonoras.

Os sinais sonoros são sons destacados, ouvidos conscientemente. Trata-se de "qualquer som para qual atenção é particularmente direcionada” (SCHAFER, 2011, p. 368). Uma forma de compreender essa noção é através da comparação com a nossa percepção visual. Quando olhamos para uma pintura, conseguimos, geralmente e sem muito 
esforço, distinguir a "figura", que é o foco da nossa atenção, do "fundo", aquilo que é considerado contexto, cenário. Ou seja, conseguimos distinguir uma determinada forma que se destaca do restante da composição em tela. O mesmo acontece com a nossa percepção auditiva. Alguns sons se destacam e atraem a nossa atenção. Esse destaque, no entanto, não está necessariamente relacionado aos aspectos físicos do som.

Não há nada a fazer com a dimensão física do som, pois já mostrei de que modo mesmo os sons muito fortes, como os da Revolução Industrial, permaneceram completamente indiscerníveis até que sua importância social começou a ser questionada. Por outro lado, mesmo os sons mais delicados serão notados como figuras quando são novidade, ou quando percebidos por forasteiros. Assim, Lara nota o ruído das luzes elétricas em Moscou tão logo Pasternak a faz mudar-se do interior para lá (Doutor Jivago), ou eu noto o rangido das pesadas cadeiras de metal no chão de ladrilhos dos cafés de Paris cada vez que visito essa cidade como turista" (SCHAFER, 2011, P. 215).

Nesse sentido, a identificação dos sinais sonoros de um lugar não pode ser realizada levando-se em consideração apenas os aspectos como o volume e a altura do som. Como o trecho acima ilustra, um som pode se destacar frente a outros que nós ouvimos por conta de uma experiência subjetiva. O tema de uma música ou um determinado tom de voz pode nos remeter a uma memória pessoal, por exemplo. Eles se destacam do "fundo" pelo significado que atribuímos a eles, sendo percebidos por nós como "figuras". Aqui, não trataremos desse aspecto. Nos interessam os sinais sonoros cujos significados são compartilhados socialmente. Aqueles sons que organizam e orientam a espacialidade de um determinado lugar, por exemplo. Como, então, identificá-los?

Primeiramente, a identificação dos sinais sonoros de um determinado lugar envolve uma análise que encare o som como um evento, ou seja, como algo que acontece em um espaço-tempo específico, em uma determinada situação, o que vai influir sobre os significados a ele atribuídos. O conjunto de sons mecânicos de um trem que se aproxima poderia ser mais um indistinguível entre tantos outros sons urbanos, mas, ele acaba se configurando como sinal sonoro para quem está habituado ao ambiente da estação e o identifica como anúncio da chegada do veículo. É neste contexto específico que esses sons assumem um determinado 
significado. A compreensão do papel que o som exerce naquela ordem espacial passa, portanto, pela consideração de um contexto.

Em segundo lugar, é preciso considerar que apesar dos sinais sonoros poderem ser "organizados dentro de códigos bastante elaborados, que permitem mensagens de considerável complexidade a serem transmitidas àqueles que podem interpretá-las" (SCHAFER, 2011, p. 27) e apesar de muitas das nossas atividades cotidianas dependerem da correta leitura dos códigos atrelados a esses sinais, nem sempre temos consciência dos significados que atribuímos aos sons que percebemos no dia-a-dia. Esse ponto coloca em dúvida a eficiência do uso de entrevistas na nossa investigação, pois, na medida que as associações entre som e significado, por não serem tão claras para todos nós, podem acabar não sendo verbalizadas nas respostas dos entrevistados. Desse modo, consideramos que a identificação dos sons fundamentais envolve não só uma escuta atenta da paisagem sonora, mas também a análise dos comportamentos a ela associados.

Se, na metáfora visual que utilizamos anteriormente, os sinais sonoros correspondem à "figura", os sons fundamentais corresponderiam ao que a chamamos de "fundo". Falamos aqui dos "sons ouvidos continuamente por uma determinada sociedade ou uma com uma constância suficiente para formar um fundo contra o qual os outros sons são percebidos" (SCHAFER, 2011, p. 368).

Para Schafer (2011, p. 26), "os sons fundamentais não precisam ser ouvidos conscientemente; eles são entreouvidos, mas não podem ser examinados, já que se tornam hábitos auditivos, a despeito deles mesmos". No entanto, sua preponderância e perenidade podem acabar gerando uma espécie de sentido de lugar (TUAN, 2013).

“Os sons fundamentais de uma paisagem são os sons criados por sua geografia e clima: água, vento, planícies, pássaros, insetos e animais. Muitos desses sons podem encerrar um significado arquetípico, isto é, podem ter-se imprimido tão profundamente nas pessoas que os ouvem que a vida sem eles seria sentida como um claro empobrecimento" (SCHAFER, 2011, p. 26).

Falamos, então, de sons e composições sonoras que, ao mesmo tempo que não capturam nosso foco de atenção, são preponderantes e perenes em um determinador lugar, ao ponto de se tornarem uma marca da identidade dos mesmos. A consideração dessa categoria pode nos permitir levantar questões como: 
quais sons ou conjuntos de sons encerram um "significado arquetípico" na área analisada? Quais sons estão "imprimidos tão profundamente" nos frequentadores desse espaço a modo de conformarem um sentido de lugar? Como veremos, em campo, podemos identificar os sons fundamentais da área de estudo a partir da escuta in loco e da gravação do som ambiente, buscando registrar quais sãos mais preponderantes e os mais perenes no local.

A última noção proposta por Schafer (2011, p. 27) é a de marca sonora. O termo em inglês, soundmark, é uma variação de landmark, e refere-se a "um som da comunidade que seja único ou que possua determinadas qualidades que o tornem especialmente significativo ou notado pelo povo daquele lugar". O badalar do sino de uma igreja em um bairro residencial e o canto de torcidas organizadas em áreas próximas a estádios de futebol são exemplos. Para a identificação das marcas sonoras, segue-se o mesmo expediente utilizado para os sons fundamentais, realizando-se os procedimentos de escuta e gravação dos sons que, pelo seu caráter endêmico e simbólico, configurem-se como verdadeiras marcas sonoras.

\footnotetext{
Ponto de audição, composição e exposição
}

Gomes (2013), para abordar as relações existentes entre espacialidade e visibilidade, fez uso de três expressões frequentemente utilizadas nos discursos sobre as artes: ponto de vista, composição e exposição. Tal uso se justifica pelo fato dessas três noções, afirma o autor, possuírem um fundamento posicional e, portanto, espacial, geográfico. Apesar de apresentar preocupações distintas das nossas e, seguindo a tradição geográfica, estar concentrado principalmente naquilo que é visível, a discussão levantada por Gomes aponta o caminho para os conceitos que podem orientar a construção de um trabalho de campo preocupado com as relações entre sons e espacialidade.

$\mathrm{Na}$ concepção do autor, ponto de vista, para além do sentido metafórico, refere-se aos lugares que oferecem uma visão panorâmica, de onde se pode observar uma paisagem, por exemplo. "Ponto" nesse caso indica um lugar determinado, uma posição da qual podemos ver algo que não veríamos se estivéssemos situados em outra posição qualquer. A expressão estabelece, portanto, uma relação direta entre o observador e aquilo que está sendo observado. O ponto de vista é, portanto, um dispositivo espacial (posicional) que nos permite ver certas coisas (GOMES, 2013, p. 19). 
Gostaríamos de propor aqui uma noção análoga a de ponto de vista: o ponto de audição. $\mathrm{O}$ argumento fundamental é que aquilo que ouvimos é, assim como aquilo que vemos, resultado também de um jogo de posições, composto por quem ouve e o que é ouvido.

Buscamos, diariamente, de forma intuitiva ou deliberada, nos posicionar de forma a ouvir ou não ouvir determinados tipos de fontes sonoras. Ao assumirmos uma posição, não estamos construindo apenas um campo de observação, mas também um campo de audição. Dessa forma, tornamos outras parcelas desse campo periféricas e emudecemos outra imensa parcela. Caminhando da entrada para o interior de uma praça, por exemplo, podemos passar, em poucos metros, de um ambiente marcado pelo som cacofônico de ambulantes, transeuntes e automóveis para um outro onde predominam os cantos dos passarinhos e o farfalhar das folhas das árvores.

A noção de ponto de audição é importante na nossa discussão por dois motivos principais. Primeiramente, pois, nos trabalhos de campo, é necessária a escolha de pontos estratégicos para a análise da paisagem sonora local. Ou seja, o geógrafo enfrenta a tarefa de selecionar pontos de audição que o permita a escuta e o registro dos sons importantes para a sua análise. Em segundo lugar, a consideração da relação entre "onde estamos" e "o que ouvimos" é importante também para compreendermos como a posição e as trajetórias desempenhadas pelas pessoas também são moduladas pelo que elas ouvem.

A composição, por sua vez, seria um conjunto estruturado de formas, cores e coisas. Gomes (2013) a define como sendo o resultado de uma combinação que produz algo novo, formado pela junção estruturada de diversos elementos. Sob essa perspectiva, a paisagem pode ser entendida, também, como uma composição. Formas de relevo, diferentes tipos de cobertura vegetal, ocupação das terras, entre muitos outros elementos, se associam de maneira original e configuram uma paisagem. E, argumenta Gomes, um aspecto fundamental da paisagem, entendida como uma composição, é o jogo de posições. A forma de dispersão desses dados que, integrados, dão origem a um novo elemento corresponde à sua espacialidade. Essa espacialidade, ou esse "padrão de dispersão”, é a marca de uma composição. Há uma ordem espacial que é a chave da composição (GOMES, 2013, p. 21-22).

O mesmo termo, composição, pode se referir também a um conjunto estruturado de sons e silêncios que, combinados, produzem algo novo. Isso parece óbvio 
quando pensamos em uma música, resultado do trabalho de um compositor. Mas podemos falar, também, do som ambiente, da paisagem sonora, como uma composição, como o resultado da combinação de "elementos que se associam de maneira original". E a forma como percebemos essa composição também é, por sua vez, modulada por um jogo de posições entre o ouvinte e as fontes sonoras. A partir de parâmetros como timbre, volume e altura, somos capazes não só identificar as fontes sonoras que ouvimos, mas também as suas posições em relação à nossa. A consideração de uma paisagem sonora como uma composição, ou seja, como o resultado de um jogo de posições entre quem ouve e quem é ouvido, é fundamental para análise da relação entre som e espacialidade na pesquisa geográfica.

A última noção apresentada por Gomes é a de exposição, a qual também é definida pela situação espacial e diz respeito a uma "posição de exterioridade". Segundo o autor, há uma delimitação que estabelece o que deve ser visto e o que não deve, e isso é o resultado de uma classificação relacionada ao espaço, é uma questão de posição. O que é exposto ganha visibilidade e tem compromisso fundamental com a ideia de que deve ser visto, olhado, observado, apreciado e, complementamos aqui, ouvido. Assim como determinados tipos de som são evitados - por serem muito incômodos, por exemplo - outros costumam ganhar exposição e são valorizados.

A identificação e análise das complexas escalas de valores e significações que estabelecem o que deve ou não ser visto e, o que mais nos interessa aqui, ouvido em um determinado lugar, pode nos auxiliar na compreensão mais aprofundada da dimensão sonora com que nos deparamos em um trabalho de campo.

\section{Caminhadas de escuta e observação}

As caminhadas sonoras (do inglês soundwalks) ou, como preferimos, caminhadas de escuta e observação ${ }^{2}$ são uma prática desenvolvida no âmbito do World Soundscape Project (WSP), grupo de pesquisa formado por Murray Schafer e colegas da Simon Fraser Universisty, no final da década de 1960, com enfoque na ecologia acústica.

Hidelgard Westerkamp (2001) definiu a caminhada sonora como sendo uma excursão cujo propósito principal seja escutar o ambiente. Na proposta original apresentada pela autora, perguntas como "quais sons eu ouço?" e "quantas fontes sonoras diferentes eu identifico?" orientariam a nossa escuta durante a caminhada. Ou seja, a atividade surgiu 
associada a uma função didática, com o propósito de educar a nossa escuta e permitir uma percepção mais consciente do ambiente sonoro ao nosso redor ou, nas palavras de Westerkamp (2001), "redescobrir e reativar a nossa capacidade de escuta”.

Apesar de aparecer, inicialmente, como prática pedagógica, esse método vem sendo adaptado e utilizado por pesquisadores com diferentes enfoques investigativos.

$\mathrm{Na}$ Geografia, temos exemplos variados da utilização desse método. Butler (2006, 2007) elaborou passeios sonoros com gravações contendo a história oral de duas rotas ao longo do rio Tâmisa, em Londres, o que demonstra o potencial que esta prática possui na discussão sobre história urbana e memória local.

Já Adams et al. (2006) conduziram caminhadas sonoras com 34 pessoas na cidade de Londres, durante o verão e o inverno. $\mathrm{Na}$ atividade, os participantes escolheram uma rota e, após uma caminhada de dez minutos, eram entrevistados a respeito das suas experiências.

Outro exemplo é o trabalho de Catherine Sémidor (2006). A autora utiliza o método de uma forma diferente dos estudos apresentados: ao invés de conduzir participantes ao longo de uma rota escolhida em uma área urbana, ela mesmo, utilizando um par de microfones binaurais ${ }^{3}$, registrou os sons encontrados ao longo do percurso. As faixas de áudio resultantes das gravações foram transformadas em duas imagens bidimensionais, uma para o ouvido esquerdo e outra para o direito, que indicavam as variações de parâmetros como frequência e intensidade do som registrado ao longo do percurso que a autora realizou na cidade de Barcelona.

Os exemplos demonstram que as caminhadas sonoras podem, além de servir a diferentes objetivos de pesquisa, assumir diferentes formatos no trabalho de campo.

Primeiramente, trata-se de um método que pode ser aplicado diretamente pelo pesquisador, que, em campo realiza suas trajetórias escutando e/ou registrando em áudio as composições sonoras encontradas na área de estudo. Pode, também, ser realizado em grupo para, por exemplo, identificar as convergências e divergências na percepção das pessoas sobre uma determinada paisagem sonora.

Em segundo lugar, as caminhadas sonoras podem ser realizadas com o objetivo a estimular a escuta in loco da paisagem sonora. Nesse caso, é importante que o pesquisador possua algum tipo de ficha de observação e uma clareza dos seus objetivos em campo, de modo a orientar a 
sua escuta e filtrar o que interessa ou não à sua investigação. Tais caminhadas podem também servir para o registro em áudio dos sons escutados em campo, para posterior análise. Em ambos os casos, a utilização de cadernetas de campo e máquinas fotográficas podem auxiliar na posterior reconstrução dos cenários nos quais aqueles sons foram emitidos.

Um terceiro aspecto a ser levado em consideração é a trajetória que realizamos nas nossas caminhadas em um trabalho de campo. Definir essa trajetória significa fazer uma seleção do que vai ser ouvido e registrado (ou o que vai estar em exposição, como colocamos antes) e o que vai ser ignorado pelos nossos ouvidos e gravadores. Assim como a definição de um roteiro define também o que se vê e o que pode se descobrir sobre um lugar, o desenho das nossas caminhadas são fundamentais na determinação dos dados que vamos coletar. Desse modo, dependendo dos nossos objetivos em um trabalho de campo, podemos considerar a possibilidade de não definir uma trajetória previamente, deixando que os sons ouvidos in loco orientem as direções que as nossas caminhadas vão tomar.

Nesse mesmo sentido, é importante considerar as vantagens de se escolher previamente um conjunto de pontos de audição que podem também nos auxiliar na coleta dos dados necessários em campo. Tais pontos podem, inclusive, estar incluídos nas rotas que traçamos em nossas caminhadas, servindo como pontos de parada onde realizamos uma descrição mais detalhada da paisagem sonora com que nos deparamos, por exemplo.

Por último, parece oportuno apresentar algumas orientações de ordem técnica no que diz à adoção de métodos fonográficos. Michael Gallagher, geógrafo e um dos maiores especialistas no tema, reúne, em seu site pessoal, uma espécie de "guia para principiantes" destinado aos pesquisadores entusiasmados em realizar gravações em seus trabalhos de campo ${ }^{4}$.

Muitas das recomendações apresentadas por Gallagher giram em torno do manuseio e configurações dos aparelhos de gravação, tais como: sempre gravar em modo estéreo e em alta qualidade; utilizar fones de ouvido para monitorar a gravação enquanto ela é realizada; e nunca ativar os controles automáticos de volume presentes em alguns aparelhos.

Outras recomendações estão mais relacionadas à forma com o campo é concebido e planejado. Destacamos, abaixo, aquelas que parecem pertinentes à discussão em curso neste artigo.

1) Pense por que você deseja fazer gravações de campo. Ter alguma noção, 
ainda que vago, do que você deseja fazer ajudará nas decisões sobre tecnologia, técnica, ética etc.

2) Comece com um gravador de áudio pequeno, acessível e fácil de transportar. É mais fácil adquirir o hábito de gravar se o seu gravador for pequeno o suficiente para carregar você, de preferência no bolso. Se o orçamento disponível for pequeno, considere utilizar um equipamento de segunda mão.

3) Pratique. Faça suas gravações, aprimore sua técnica, experimente. Mais importante do que possuir um bom equipamento, é encontrar formas criativas e engenhosas de se registrar com qualidade o que se deseja.

4) Escute. Esqueça a gravação por um tempo, encontre um espaço em que esteja interessado e ouça. A gravação em campo é, sob muitos aspectos, uma arte de atenção e paciência, semelhante à observação de pássaros. Depois de ouvir algo interessante, pense na melhor forma de gravá-lo.

\section{Conclusões}

Como afirmamos anteriormente, uma análise geográfica se delineia quando a nossa questão central está preocupada a ordem espacial dos fenômenos estudados. Ou seja, haverá sempre uma geografia quando a dispersão espacial constituir a questão central do nosso problema.

Por consequência, é a espacialidade o principal aspecto que vai diferenciar o trabalho de campo dos geógrafos frente aos outros. Vamos a campo para responder questões a respeito da ordem espacial dos fenômenos que estudamos. Seja através da coleta de amostras de solo ou de entrevistas e da elaboração de croquis, visitamos nossas áreas de estudo para obter dados que nos permitam elaborar modelos, gráficos, mapas e outras representações do objeto de estudo nos quais a sua espacialidade figure um aspecto fundamental para a sua compreensão.

$$
\text { Em resumo, retomando os }
$$
apontamentos de Driver (2000), vamos a campo para realizar um conjunto de práticas que nos permitam compreender, analisar e representar o fenômeno estudado, sempre a partir de uma perspectiva espacial.

Vamos a campo, também, para "ver" o que estamos estudando. Seja de forma exploratória e pouco estruturada, seja utilizando fichas de observação, máquinas fotográficas e outros equipamentos e estratégias de visualização do mundo. "Ver", aqui, é uma metáfora para abordagem empírica, mas é, também, uma referência ao peso que damos aos métodos 
visuais de produção e comunicação do conhecimento na Geografia.

Diante deste quadro, o presente artigo procurou demonstrar que os geógrafos podem incorporar métodos fonográficos ao seu repertório, romper com o "ocularcentrismo" vigorante na disciplina e, ainda assim, manter-se alinhados ao que se pode esperar de um trabalho de campo na Geografia.

Isso, pois, conceitos como o de paisagem sonora e noções como o de ponto de audição, composição e exposição revelam relações intrínsecas entre som e espacialidade. $\mathrm{O}$ arcabouço teórico oferecido por Murray Schafer e os diferentes tipos de práticas, exemplificadas aqui pelas caminhadas de escuta e observação, podem nos auxiliar a compreender tais relações e a realizar novas descobertas sobre os nossos objetos de estudo.

\section{NOTAS}

* Mestre em Geografia pelo PPGG-UFRJ, doutorando do PPGG-UFRJ, membro do Grupo de Pesquisa Território e Cidadania. natocoimbra@gmail.com

${ }^{1} \mathrm{O}$ objetivo inicial de Schafer ao iniciar seus estudos acústicos, era a fundação de uma nova interdisciplina com o objetivo de "descobrir princípios pelos quais a qualidade estética do ambiente acústico, ou paisagem sonora, pode ser melhorado”. Para isso, ressaltava o autor, seria "necessário conceber a paisagem sonora como uma vasta composição musical que ressoa incessantemente à nossa volta e perguntar de que modo sua orquestração e sua forma podem ser aperfeiçoadas para produzir riqueza e diversidade de efeitos que não sejam, todavia, destrutivos para a saúde ou o bem-estar humano (SCHAFER, 2011, p. 366)". Ou seja, sua motivação inicial era o desenvolvimento de um campo de estudos que teria uma finalidade prática, a saber, a melhoria da qualidade do ambiente sonoro que moldamos cotidianamente.

${ }^{2} \mathrm{O}$ termo soundwalks vem sendo para o portugês como caminhadas sonoras (MALANSKI, 2017; HOLANDA e BARTHOLO 2017) e cobre uma gama muito diversificada de práticas pedagógicas, científicas e artísticas (NAKAHODO, 2014). Em outra ocasião (FRIAS, 2018), utilizamos a expressão caminhadas de escuta e observação e acreditamos que, assim, estamos sendo, o mesmo, mais preciso quanto aos propósitos do método.

${ }^{3}$ A gravação de áudio binaural é uma técnica que permite registrar os sons na forma como os percebemos em um ambiente, preservando aspectos que nos permitem perceber a distância e o posicionamento preciso das fontes sonoras, por exemplo. Isso é possível quando gravamos o som ambiente com um par de microfones instalados na posição dos nossos ouvidos. Assim, quando utilizamos fones-de-ouvido para escutar a faixa de áudio gerada na gravação, temos uma experiência auditiva muito semelhante àquela do ambiente original.

4 Disponível em

http://michaelgallagher.co.uk/how-to/startingout-with-field-recording. Acessado em 16/01/2020 ${ }^{8}$ Articulação Nacional de Transgêneros. 


\section{REFERÊNCIAS BIBLIOGRÁFICAS}

ADAMS M; COX T; MOORE G; CROXFORD B; REFAEE M; SHARPLES S (2006) Sustainable soundscapes: Noise policy and the urban experience. Urban Studies, v. 43, n. 13, p 23852398, 2006.

ALENTEJANO, P R e ROCHA-LEÃO, O (2004) O trabalho de campo: uma ferramenta essencial pás os geógrafos ou um instrumento banalizado? Boletim Paulista de Geografia. São Paulo (84): 51-67.

ANDERSON B, MORTON F, and REVILL G (2005) Practices of music and sound. Social and Cultural Geography 6:639-644.

ANDERSON B (2004) Recorded music and practices of remembering. Social and Cultural Geography 5: 3-20.

BOLAND P (2010) Sonic geography, place and race in the formation of local identity: Liverpool and Scousers. Geografiska Annaler: Series B, Human Geography 92: 1-22.

BULL M (2000) Sounding out the City: Personal Stereos and the Management of Everyday Life. Oxford: Berg.

BUTLER T (2006) A walk of art: The potential of the soundwalk as practice in cultural geography. Social and Cultural Geography 7: 889-908.

BUTLER T (2007) Memoryscape: How audio walks can deepen our sense of place by integrating art, oral history and cultural geography. Geography Compass 1: 360-372.

CORBIN A (1998) Village Bells: Sound and Meaning in the 19th-Century French Countryside. New York: Columbia University Press.

COSGROVE D (1985) Prospect, perspective and the evolution of landscape idea. Transactions of the Institute of British Geographers, 10(1) NS.

DENORA $\mathrm{T}$ (2000) Music in Everyday Life. Cambridge: Cambridge University Press.

DRIVER F (2000). Editorial: Field-work in
Geography. Transactions. Institute of British Geographers 25(3): 267-268.

FRIAS R C (2018). Uma trilha sonora no largo da carioca: caminhadas de escuta e observação como método de investigação dos espaços públicos. Geografares, (26), 235-253.

GALLAGHER M e PRIOR J (2014) Sonic geographies: Exploring phonographic methods. Progress in Human Geography 38: 267 - 284.

GALLAGHER M (2011) Sound, space and power in a primary school. Social and Cultural Geography 12: 47-61.

GREGORY D (1994). Geographical Imaginations. Oxford: Blackwell, 1994.

GOMES P C C (2009) Um lugar para a Geografia: Contra o simples, o banal e o doutrinário. In: Espaço e Tempo: Complexidade e desafios do pensar e fazer geográfico. Curitiba: Ademadan.

GOMES P C C (2013) O Lugar do Olhar. Rio de Janeiro: Bertrand Brasil.

GOMES P C C e Ribeiro L P (2013) A produção de imagens para a pesquisa em Geografia. Espaço $e$ Cultura 33: 27-42.

HOLANDA C; BARTHOLO R. Sondando a cidade. Memória, cartografias e caminhadas sonoras. Revista Z Cultural, Rio de Janeiro, v. 12, n.2, sem paginação, 2017.2 Disponível em http://revistazcultural.pacc.ufrj.br/sondando-acidade-memoria-cartografias-e-caminhadassonoras/. Acessado em 15/01/2020.

JONES K (2005) Music in factories: A twentiethcentury technique for control of the productive self. Social and Cultural Geography 6: 723-744.

KRAUSE B (2013). A grande orquestra da natureza: descobrindo as origens da música do mundo. Rio de Janeiro: Zahar.

LACOSTE, Y. (2006 [1977]) A pesquisa e o trabalho de campo: um problema político para os pesquisadores, estudantes e cidadãos. Boletim Paulista de Geografia. São Paulo (84): 77-92. 
LATOUR, B (2001 [1999]) A esperança de Pandora: ensaios sobre a realidade dos estudos científicos. Bauru: EDUSC.

LEHR JC (1983) Texas (when I die) - national identity and images of place in Canadian country music broadcasts. The Canadian Geographer - Le Ge'ographe canadien 27: 361-370.

LORIMER H (2007) Songs from before - shaping the conditions for appreciative listening. In: Gagen E, Lorimer H, and Vasudevan A (eds) Practising the Archive: Reflections on Method and Practice in Historical Geography. London: Historical Geography Research Group, Royal Geographical Society, Institute of British Geographers, 57-73.

MALANSKI L (2017) O interesse dos geógrafos pelos sons: alinhamento teórico e metodológico para estudos das paisagens sonoras. Revista Ra'eGa, Curitiba, v. 40, p. 145-162, 2017.

MATLESS D (2005) Sonic geography in a nature region. Social and Cultural Geography 6: 745-766.

NAKAO NAKAHODO L (2014) As paisagens do corpo na criação sonora. Revista POLÊMICA, Rio de Janeiro, v. 13, sem paginação. Disponível em: https://goo.gl/x168AV. Acessado em 15/11/2017.

NOVAES A (2011) Uma Geografia Visual? Contribuições para o uso das imagens na difusão do conhecimento geográfico. ESPAÇO E CULTURA, UERJ, RJ, N. 30, P.6-22, JUL./DEZ.

PRICE, M D (2001) The kindness of strangers. In: The Geographical Review, no 91 (1-2), pp. 143-150.

PORTEOUS D (10985) Smellscape. Progress in physical geography, v.9 (3).

ROSE, Gillian. On the need to ask how, exactly, is geography "visual"? Antipode, v. 35(2), pp. 212-22, 2003.

RYAN J (1997. Picturing Empire: Photography and the Visualization of the British Empire. London: Reaktion Books.
SAUER C O (1998 [1925]) A morfologia da Paisagem. In: CORREAA R L; ROSENDAHL Z (Org.). Paisagem, tempo e cultura. Rio de Janeiro: EdUERJ, p.12-74.

SCHAFER R M (2011 [1977]). A Afinação do Mundo. São Paulo: Editora Unesp.

SÉMIDOR (2006) Listening to a city with the soundwalk method. Acta Acustica United with Acustica 92: 959-964.

SERPA, A (2006) O trabalho de Campo em geografia: uma abordagem teórico-metodológica. Boletim Paulista de Geografia (84): 7-24.

SMITH, B (2004). Listening to the wild blue yonder: The challenges of acoustic ecology. In: ERLMANN, V. (ed.) Hearing Cultures: Essays on Sound, Listening and Modernity. Oxford: Berg, pp. 21-42.

SMITH S (2000). Performing the (sound) world. Environment and Planning D: Society and Space, v 18, p. 615-637.

WESTERKAMP (2001) Soundwalking. Disponível em

http://www.sfu.ca/*westerka/writings\%20page/a rticles\%2opages/soundwalking.html.

THIBAUD J P (2011) A Sonic Paradigm of Urban Ambiances. Journal of Sonic Studies, n. 1, pp. 1-14. TORRES M (2010) Paisagens sonoras: possíveis caminhos aos estudos culturais em Geografia. Revista RA'EGA, n. 20, pp. 123-132.

TUAN Y (2013 [1977]) Espaço e lugar: a perspectiva da experiência. Londrina: Eduel.

WISSMANN (2014) Geographies of urban sound. Farnham: Ashgate.

WYLIE (2007). Landscape. New York: Routledge.

ZUSMAN P (2011) La tradición del trabajo de campo en Geografía. Geograficando, 7 (7), 15-32. En Memoria Académica. Disponível em: http://www.memoria.fahce.unlp.edu.ar/art_revist as/pr.5089/pr.5089.pdf. Acessado em 12/01/2020. 


\section{FIELDWORK IN GEOGRAPHY: FUNDAMENTAL ASPECTS AND AN INVITATION TO LISTENING}

ABSTRACT: THIS ARTICLE ATTENDS A DUAL PURPOSE. FIRST IS TO DISCUSS THE SPECIFICITIES OF FIELDWORK IN GEOGRAPHY. TO THIS END, A HISTORICAL OVERVIEW AND A BIBLIOGRAPHIC REVIEW ON THE ROLE OF FIELDWORK IN

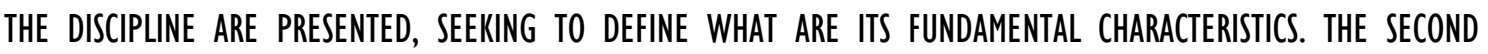
OBJECTIVE IS TO PRESENT ANALYSIS TOOLS, CONCEPTS AND RESEARCH PRACTICES THAT ALLOW GEOGRAPHERS TO CARRY OUT FIELDWORK FOCUSED ON THE STUDY OF THE WORLD'S SOUNDS. IN THIS DIRECTION, WE DISCUSS THE CENTRAL ROLE THAT THE VISION HAS IN THE PRODUCTION AND COMMUNICATION OF GEOGRAPHICAL KNOWLEDGE, IN ORDER TO DEMONSTRATE, THEN, THE POSSIBILITIES THAT OPEN UP WHEN WE ALSO CONSIDER OUR LISTENING. FINALLY, WE PRESENT A SELECTED SET OF NOTIONS, CONCEPTS AND FIELD PRACTICES thAT CAN ASSIST IN PLANNING AN EMPIRICAL INVESTIGATION DEDICATED TO SOUND AND SPATIALITY.

KEYWORDS: FIELDWORK; SOUNDSCAPE; PHONOGRAPHIC METHODS; SOUNDWALK.

\section{EL TRABAjO DE CAMPO EN GEOGRaFía: CARACTERísticas fundaMENTALES Y UNA}

\section{INVITACIÓN A LA ESCUCHA}

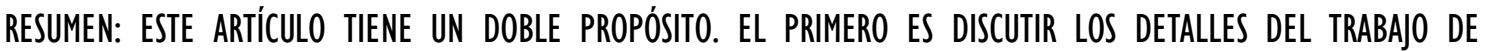
CAMPO EN GEOGRAFía. CON ESTE FIN, SE PRESENTA UN RESUMEN HISTÓRICO Y UNA REVISIÓN BIBLIOGRÁFICA SOBRE el papel del trabajO de campo en la disciplina, buscando definIR Cuáles son sus características FundaMENTALES. EL SEGUNDO OBJETIVO ES PRESENTAR hERRAMIENTAS DE ANÁLISIS, NOCIONES Y PRÁCTICAS DE INVESTIGACIÓN QUE PERMITAN a lOS GEÓGRAFOS lLEVAR A CABO UN TRABAJO DE CAMPO CENTRADO EN EL ESTUDIO DE LOS SONIDOS DEL MUNDO. PARA ESTO, DISCUTIMOS EL PAPEL CENTRAL QUE tIENE LA VISIÓN EN LA PRODUCCIÓN Y COMUNICACIÓN DEL CONOCIMIENTO GEOGRÁFICO, PARA DEMOSTRAR, A CONTINUACIÓN, LAS POSIBILIDADES QUE SE 
ABREN CUANDO TAMBIÉN CONSIDERAMOS NUESTRA ESCUCHA. FINALMENTE, SE PRESENTA UN CONJUNTO SELECCIONADO DE NOCIONES, CONCEPTOS Y PRÁCTICAS DE CAMPO QUE PUEDEN AYUDAR A PLANIFICAR UNA INVESTIGACIÓN EMPÍRICA DEDICADA AL SONIDO Y LA ESPACIALIDAD.

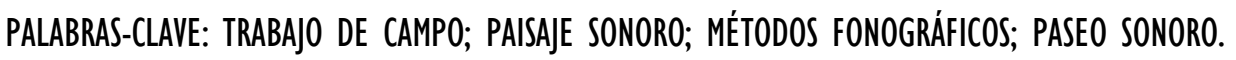

